\title{
Medical and Technical Requirements to the Basic Ration of the Most Advanced Man-Rate Ferry Ship Crew and Products Contained Radioprotective Characteristics
}

Добровольский В.Ф., Агуреев А.Н. Dobrovolsky V.F., Agureev A.N.

\author{
Ключевые слова: \\ медико-технические \\ требования; \\ рацион питания; \\ пилотируемый \\ транспортный \\ корабль нового \\ поколения; \\ радиопротекторные \\ свойства; \\ космический полет; \\ системы обеспечения \\ питанием
}

\begin{abstract}
Реферат
В статье рассмотрены вопросы разработки медико-технических требований (МТT) к базовому рациону питания экипажа пилотируемого транспортного корабля нового поколения (ПТК НП) с включением в его состав продуктов с радиопротекторными свойствами. Назначение разработки - создание продуктов и рационов питания, физиологически полноценных, сбалансированных по содержанию незаменимых пищевых веществ, обеспечивающих сохранение здоровья и работоспособность экипажей при воздействии на организм повышенных уровней ионизирующей радиации и других неблагоприятных факторов окружающей среды в космическом полете. Сбалансированность потребляемой пищи является непременным условием, позволяющим в наибольшей степени обеспечить удовлетворение потребности организма в пищевых и биологически активных веществах. Для ускорения процессов адаптации организма космонавтов к экстремальным условиям космического полета продукты должны создаваться из легкоусвояемых компонентов, не вызывающих функционального напряжения органов пищеварения и способствующих коррекции возможных изменений, возникающих в этот период. Продукты должны изготавливаться на основе натурального сырья, содержащего, кроме биологически полноценных белков, жиров и углеводов, минеральные элементы в легкоусвояемой форме (в первую очередь, соли калия, кальция, фосфора, магния), витамины (особенно группы В и токоферолы), моносахариды, полиненасыщенные жирные кислоты, тонизирующие и другие биологически активные вещества. МТТ отражают показатели, полученные в ходе анализа литературных источников, а также результаты модельных наземных экспериментов и данные реальных космических полетов на транспортных космических кораблях и орбитальных космических станциях.
\end{abstract}

\section{Abstract}

This article concerns the development of the medical and technical requirements (MTR) to the basic ration of the most advanced man-rate ferry ship and products contained radioprotective characteristics. The development purpose is to create food and food

diet;

Keywords:

medical and technical requirements;

,

Добровольский В.Ф., Агуреев А.Н. Медико-технические требования к базовому рациону питания экипажа пилотируемого транспортного корабля нового поколения и продуктам, обладающим радиопротекторными свойствами // Индустрия питания |Food Industry. 2018. T. 3. № 2. C. 4-8. DOI: 10.29141/2500-1922-2018-3-2-1. 
rations that are physiologically complete, balanced with the essential nutrients ensuring the health and efficiency preservation of the crew while exposing to high levels of ionizing radiation and other adverse environmental factors in space flight. The balance of consumed food is an essential condition that allows ensuring the greatest extent to meet the body needs in food and biologically active substances. To accelerate the processes of astronaut body adaptation to the extreme conditions of space flight, products should be easily digestible. Its components do not cause functional stress of the digestive organs and contribute to the correction of possible changes that occur during this period. The product basis is to be made of natural raw materials containing, in addition to biologically full proteins, fats and carbohydrates, mineral elements in easily digestible form (primarily potassium, calcium, phosphorus, magnesium), vitamins (especially groups $B$ and tocopherols), monosaccharides, polyunsaturated fatty acids, antifatigue and other biologically active substances. The MTR reflects the analysis data of literature sources, as well as the results of model ground experiments and data of the real space flights on transport spacecrafts and orbital space stations. most advanced man-rate ferry ship; radioprotective properties; space flight; food supply system

\section{Медицинские требования}

В основу разработки рационов питания (РП) как важнейшего компонента системы обеспечения питанием (СОП) экипажей пилотируемых транспортных кораблей нового поколения (ПТК НП) должен быть положен принцип сбалансированного питания в соответствии с потребностями организма человека.

Сбалансированность потребляемой пищи - непременное условие, позволяющее в наибольшей степени обеспечить удовлетворение потребности организма человека в пищевых и биологически активных веществах $[1 ; 2 ; 6 ; 10]$.

Для ускорения процессов адаптации организма к экстремальным условиям космического полета продукты должны создаваться из легкоусвояемых компонентов, не вызывающих функционального напряжения органов пищеварения и способствующих коррекции возможных изменений, возникающих в этот период.

Продукты должны изготавливаться на основе натурального сырья, содержащего, кроме биологически полноценных белков, жиров и углеводов, минеральные элементы в легкоусвояемой форме (в первую очередь, соли калия, кальция, фосфора, магния), витамины (особенно группы В и токоферолы), моносахариды, полиненасыщенные жирные кислоты, тонизирующие и другие биологически активные вещества $[1 ; 9]$.

Большая часть полета ПТК НП происходит в период острой адаптации к условиям невесомости, который в зависимости от индивидуальных особенностей организма человека длится от 2 до 8 суток: у космонавтов значительно снижается физическая и психическая работоспособность, отмечаются проявления «болезни движения».

С целью минимизации проявлений «болезни движения" и сохранения работоспособности экипажей необходимо разработать и включить в состав рациона набор продуктов для периода острой адаптации, а именно: блюда жидкой или пюреобразной консистенции; горячие напитки (чай, кофе); фруктовые и ягодные соки; творожные пасты с различными пюреобразными фруктово-ягодными добавками [3; 12].

Для обеспечения безопасности экипажей ПТК НП при прохождении радиационных поясов необходимо разработать и ввести в состав рациона продукты, обладающие радиопротекторными свойствами.

Основные принципы радиопротекторного питания:

- увеличение в рационе питания космонавтов белков животного происхождения (мясо, рыба, печень, творог, яйца). Общее количество белка в рационе должно составлять 15-17 \% общей энергетической ценности рациона, а соотношение «животный белок : растительный белок» должно быть $1: 1[1 ; 2 ; 3]$;

- потребление жира, не превышающее норму физиологической потребности в нем. Соотношение растительного и животного жиров должно составлять $1: 3[1 ; 2 ; 3 ; 7 ; 8]$.

- введение в рацион блюд из гороха и бобовых культур (содержат пищевые вещества, оказывающие радиопротекторное действие);

- введение в рацион молочного жира, продуктов, богатых бета-каротином (морковь, свекла, другие овощи и фрукты), подсолнечного масла, грецких орехов, отвара шиповника с целью повышения активности антиокислительной системы организма. В общей сложности в диете должно быть увеличено содержание витаминов С и А (суммарно с бета-каротином) в 2 раза, а витамина Е - в 3 раза (относительно физиологической потребности организма в этих витаминах-антиоксидантах) $[1 ; 2 ; 8]$; 
- введение витаминов $\mathrm{B}_{1}, \mathrm{~B}_{2}, \mathrm{~B}_{6}$, пантотеновой кислоты (витамин $B_{5}$ ), биотина (витамин H) не только для выполнения кофакторной функции в метаболических процессах в организме, но и для участия в обмене серосодержащих аминокислот и гистамина, что вызывает самостоятельный радиопротекторный эффект. Витамин В 6 является дополнительным источником серы, а витамин $\mathrm{B}_{1}$ обладает способностью потенцировать радиопротекторный эффект других пищевых веществ. Витамины группы В содержатся в крупах (гречневая, овсяная, пшеничная, рис), картофеле, горохе, фасоли, кукурузе, моркови, капусте, тыкве, грецких орехах, сое. Пантотеновая кислота содержится в мясе (говядина, телятина, баранина), а биотин - в яйцах и твороге $[9 ; 11 ; 13 ; 14]$;

- введение с целью профилактики поражения щитовидной железы органического йода с пищей (морепродукты, морская капуста, морская рыба) $[1 ; 2 ; 3 ; 4]$;

- введение пищевых волокон, которые благодаря большому радиопротекторному действию в кишечнике связывают радионуклиды и токсичные продукты радиолиза и ускоряют их выведение из организма (содержатся в моркови, свекле, яблоках, сливах, абрикосах, сухофруктах, пищевых пшеничных отрубях) [7; 9];

- обогащение рациона солями калия (сухофрукты, в первую очередь курага и изюм; белокочанная и цветная капуста; картофель; другие овощи и фрукты) и кальция (молочные продукты) способствуют вытеснению из организма радионуклидов - цезия и стронция.

Для повышения устойчивости организма членов экипажа ПТК НП к сенсорным нарушениям, оказания профилактического эффекта на пищеварительную систему и нормализации функциональной активности других жизненно важных систем организма необходимо разработать и ввести в состав рацион продукты, обогащенные биологически активными компонентами, так называемые функциональные продукты [1-3; 6-8]:

- в качестве базовых функциональных продуктов целесообразно использовать каши на основе злаковых культур: овсяные, кукурузные, гречневые. При этом масса сухого базового продукта должна составлять не менее 70 г;

- для повышения биологической активности продуктов в их состав необходимо ввести продукты, богатые пектином фрукты, ягоды, редис, морковь, свеклу. Пектиновые вещества не только адсорбируют экзо- и эндогенные токсины, соли тяжелых металлов, способствуют выведению радионуклидов из организма, но и участвуют в регуляции перистальтики кишечника, оказывают нормализующее влияние на моторную функцию желчевыводящих путей, стимулируя процессы выведения желчи и препятствуя развитию застойных явлений в гепатобилиарной системе. Указанные свойства пектинов наделяют содержащие их продукты нормализующим влиянием на деятельность органов пищеварительной системы;

- для поддержания водно-солевого гомеостаза и коррекции энергетического обмена следует учитывать исключительно важную роль соединений натрия (гидрокарбонаты, фосфаты) в образовании буферной системы, обеспечивающей кислотно-щелочное равновесие в организме. Соединения натрия содержатся в мясе птицы, говядине, баранине, креветках, кальмарах, рыбе, яйцах, молочных продуктах, бобовых, орехах, овощах, фруктах и ягодах.

- соли калия (их содержат бобовые, сухофрукты, орехи, рыба и морепродукты) играют важную роль во внутриклеточном обмене, участвуя в ферментативных процессах и превращении фосфопировиноградной в пировиноградную кислоту, которая служит основой для образования богатых энергией соединений - АТФ;

- соединения магния, наряду с калием, кроме участия в поддержании постоянства внутренней среды организма, выполняют важную функцию нормализации деятельности сердечно-сосудистой системы. Соединения магния также играют важную роль в образовании металлоферментных комплексов, участвующих в обменных процессах (прежде всего, в углеводном и жировом обмене). Богаты соединениями магния неочищенные отруби злаковых и орехи;

- рекомендуется вводить в рацион экипажей соединения меди, марганца, цинка, селена, кремния, так как имеются данные о тесной связи фосфорно-кальциевого обмена с микроэлементами. Наличие в продуктах питания, наряду с витаминами, указанных элементов придает им антиоксидантные свойства и способствует коррекции обменных процессов, нормализации деятельности сердечно-сосудистой системы, повышению иммунной устойчивости организма. Антиоксидантная защита организма снижает вероятность развития ишемической болезни сердца, атеросклероза и других заболеваний;

- для профилактики сенсорных нарушений, кроме вышеперечисленных элементов, регулирующих водно-солевой гомеостаз, в составе базовых продуктов должны содержаться дополнительные количества витамина В бовые, овощи, грецкие орехи, соя).

Энергетическая ценность рациона питания для экипажей ПТК НП должна находиться в пределах 2 700-3 000 Ккал; белки должны обеспечивать 15-17\% суточной калорийности рациона, жиры 30-35 и углеводы 50-55 \% [2; 3; 4; 10;11]. 
Продукты, входящие в рацион питания, должны обеспечивать физиологическую потребность организма человека в макро-и микроэлементах, а также в витаминах. С этой целью можно использовать различные полноценные витаминно-минеральные комплексы.

Таким образом, подбор и включение в состав рациона питания новых видов продуктов, обладающих радиопротекторными свойствами и лечебно-профилактическим действием, значительно расширят арсенал средств для защиты организма от ионизирующей радиации и для алиментарной коррекции метаболических процессов и профилактики функциональных изменений, развивающихся в организме человека при воздействии экстремальных факторов космического полета.

Технические требования

Для обеспечения питанием экипажей ПТК НП при продолжительности полета до 14 до 30 суток технические элементы системы обеспечения питанием (СОП) должны быть дополнены блоком подогрева и раздачи воды. Это позволит значительно расширить ассортимент продуктов, используемых для комплектации рационов за счет продуктов сублимационной сушки, и создать физиологически полноценный рацион с первыми и вторыми горячими блюдами, а также фруктово-ягодными соками с мякотью $[4 ; 5]$.

Возможность обеспечения приемов горячей пищи позволит увеличить сроки использования рационов питания для экипажей ПТК НП до 30 суток $[4 ; 5]$.

Комплектация рационов питания для экипажей ПТК НП должна производиться продуктами,

\section{Библиографический список}

1. Агуреев А.Н. Основные итоги эксплуатации системы обеспечения питанием (СОП) экипажей МКС. Международная космическая станция, Российский сегмент. М.: Научная книга, 2011. Т. 1. C. 342-356.

2. Агуреев А.Н. Питание космонавтов от Ю.А. Гагарина до настоящих дней // Гагаринский сборник: материалы XXXVIII общественно-научных чтений, посвященных памяти Ю.А. Гагарина. Воронеж, 2011. С.100-113.

3. Агуреев А.Н. Система обеспечения космических экипажей питанием // Космическая медицина и биология. Воронеж: Научная книга, 2013. С. 94-110.

4. Агуреев А.Н., Афонин Б.В., Седова Е.А., Соловьева А.А., Валуев В.А., Сидоренко Л.А. Пищевой статус в эксперименте со 105-суточной изоляцией на первом этапе проекта «Марс500» // Авиакосмическая и экологическая медицина. 2015. № 6. C. 19-28.

5. Агуреев А.Н., Каландаров С. Обеспечение питания экипажей на ОС «Мир» // Орбитальная станция «Мир» (Космическая 6иология и медицина): в 2 т. М.: Изд-во 000 «Аником», 2001. Т. 1. С. 455-481. сохраняющими биологическую полноценность и безопасность в течение длительного (не менее 15 месяцев) времени хранения в условиях нерегулируемой температуры и влажности. Продукты должны быть простыми в приготовлении: космонавты должны иметь возможность употреблять их в условиях невесомости как в подогретом, так и в холодном виде $[2 ; 3 ; 13 ; 14]$.

Упаковка продуктов должна иметь минимальную массу и в то же время обладать достаточным запасом прочности, чтобы выдерживать воздействие перегрузок (ускорений) и вибраций, возникающих на участке выведения космического корабля на орбиту, а также сохранять герметичность при воздействии пониженного барометрического давления.

Упаковка продуктов должна, кроме прочего, выполнять функцию посуды для приготовления и приема пищи.

Материалы, из которых создана упаковка, не должны выделять в атмосферу вредные примеси, резкие запахи; они должны быть пожарои взрывобезопасными и иметь разрешение органов Госсанэпиднадзора РФ на контакт с пищевыми продуктами [4].

Фасовка продуктов должна производиться порционно из расчета одна упаковка на один прием пищи для одного человека.

На каждой упаковке продукта питания космонавтов должны быть нанесены следующие сведения: название продукта и его масса; срок изготовления и конечный срок реализации; количество воды (горячей или холодной), необходимое для восстановления продукта, и время восстановления.

\section{Bibliography}

1. Agureev A.N. Osnovnye itogi jekspluatacii sistemy obespechenija pitaniem (SOP) jekipazhej MKS. Mezhdunarodnaja kosmicheskaja stancija, Rossijskij segment. M.: Nauchnaja kniga, 2011. T. 1. S. 342-356.

2. Agureev A.N. Pitanie kosmonavtov ot Ju.A. Gagarina do nastojashhih dnej // Gagarinskij sbornik: materialy HHHVIII obshhestvenno-nauchnyh chtenij, posvjashhennyh pamjati Ju.A. Gagarina. Voronezh, 2011. S.100-113.

3. Agureev A.N. Sistema obespechenija kosmicheskih jekipazhej pitaniem // Kosmicheskaja medicina i biologija. Voronezh: Nauchnaja kniga, 2013. S. 94-110.

4. Agureev A.N., Afonin B.V., Sedova E.A., Solov'eva A.A., Valuev V.A., Sidorenko L.A. Pishhevoj status v jeksperimente so 105-sutochnoj izoljaciej na pervom jetape proekta «Mars-500» // Aviakosmicheskaja i jekologicheskaja medicina. 2015. № 6. S. 19-28.

5. Agureev A.N., Kalandarov S. Obespechenie pitanija jekipazhej na OS «Mir» // Orbital'naja stancija «Mir» (Kosmicheskaja biologija i medicina): v 2 t. M.: Izd-vo 000 «Anikom», 2001. T. 1. S. 455-481. 
6. Агуреев А.Н., Каландаров С., Богатова Р.И., Кривицина 3.А., Васильева В.Ф. Разработка базового рациона из продуктов серийного производства для питания в наземных модельных экспериментах // Авиакосмическая и экологическая медицина. 2005. № 3. С. 42-45.

7. Агуреев А.Н., Каландаров С., Васильева В.Ф., Гурова Л.А. Питание экипажей длительных экспедиций на международной космической станции // Авиакосмическая и экологическая медицина. 2004. № 5. С. 19-23.

8. Добровольский В.Ф. Использование современных технологий для разработки и обеспечения питанием космонавтов // Индустрия питания. 2016. № 1(1). С. 33-36.

9. Добровольский В.Ф. «Космическая» пища: вчера, сегодня, завтра // Пищевая промышленность. 2009. № 8. С. 53.

10. Добровольский В.Ф. Питание космонавтов: монография. М.: Лион Принт, 2000. 155 с.

11. Добровольский В.Ф., Гурова Л.А., Колесникова В.Б., Павлова Л.П. НИИ Пищеконцентратной промышленности и специальной пищевой технологии - космосу // Пищевая промышленность. 2016. № 1. С. 48-50.

12. Добровольский В.Ф., Павлова Л.П., Лукьянова Л.В., Евстигнеева Н.И. Продукты космического питания - кисели плодовоягодные сублимационной сушки // Пищевая промышленность. 2013. № 8. C. 26-28.

13. Agureev A.N. (RF), Kloeris V., Zwart S.R., Smith S.M. (US). Nutrition for International Space Station // Space biology and medicine. Vol. V. US and Russian cooperation in Space Bioligy and Medicine. American Institute of Aeronautics and Astronautics. Reston, Virginia. 2009. P. 313-324.

14. Bourland C., Kloeris V., Rice B, Vodovotz Y. Food systems for space and planetary flights / ed. H.W. Lane, D.A. Schoeller. Nutrition in space flight and weightlessness models. Boca Raton, FL: CRC Press, 2000. P. $19-40$.
6. Agureev A.N., Kalandarov S., Bogatova R.I., Krivicina Z.A., Vasil'eva V.F. Razrabotka bazovogo raciona iz produktov serijnogo proizvodstva dlja pitanija v nazemnyh model'nyh jeksperimentah // Aviakosmicheskaja i jekologicheskaja medicina. 2005. № 3. S. 42-45.

7. Agureev A.N., Kalandarov S., Vasil'eva V.F., Gurova L.A. Pitanie jekipazhej dlitel'nyh jekspedicij na mezhdunarodnoj kosmicheskoj stancii // Aviakosmicheskaja i jekologicheskaja medicina. 2004. № 5. S. 19-23.

8. Dobrovol'skij V.F. Ispol'zovanie sovremennyh tehnologij dlja razrabotki i obespechenija pitaniem kosmonavtov // Industrija pitanija. 2016. № 1(1). S. 33-36.

9. Dobrovol'skij V.F. «Kosmicheskaja» pishha: vchera, segodnja, zavtra // Pishhevaja promyshlennost'. 2009. № 8. S. 53.

10. Dobrovol'skij V.F. Pitanie kosmonavtov: monografija. M.: Lion Print, 2000. $155 \mathrm{C}$.

11. Dobrovol'skij V.F., Gurova L.A., Kolesnikova V.B., Pavlova L.P. NII Pishhekoncentratnoj promyshlennosti i special'noj pishhevoj tehnologii - kosmosu // Pishhevaja promyshlennost'. 2016. № 1. S. $48-50$.

12. Dobrovol'skij V.F., Pavlova L.P., Luk'janova L.V., Evstigneeva N.I. Produkty kosmicheskogo pitanija - kiseli plodovojagodnye sublimacionnoj sushki // Pishhevaja promyshlennost'. 2013. № 8. S. 26-28.

13. Agureev A.N. (RF), Kloeris V., Zwart S.R., Smith S.M. (US). Nutrition for International Space Station // Space biology and medicine. Vol. V. US and Russian cooperation in Space Bioligy and Medicine. American Institute of Aeronautics and Astronautics. Reston, Virginia. 2009. P. 313-324.

14. Bourland C., Kloeris V., Rice B, Vodovotz Y. Food systems for space and planetary flights / ed. H.W. Lane, D.A. Schoeller. Nutrition in space flight and weightlessness models. Boca Raton, FL: CRC Press, 2000. P. $19-40$.

\section{Добровольский Виктор Францевич}

Dobrovolsky

Viktor Francevich

Тел./Phone: (495) 383-14-92

E-mail:niippspt@gmail.com

\section{Агуреев Александр Никитович}

Agureev Aleksandr Nikitovich

Тел./Phone: (499) 195-02-43 E-mail: agureev@imbp.ru
Академик Российской академии космонавтики имени К.Э. Циолковского, заслуженный деятель науки РФ, дважды лауреат премии Правительства РФ в области науки и техники, доктор технических наук, профессор, Главный конструктор космического питания, директор Научно-исследовательский институт пищеконцентратной промышленности и специальной пищевой технологии - филиал ФГБУН «ФИЦ питания и биотехнологии» 142718, РФ, Московская область, Ленинский район, пос. Измайлово, 22

Academician of the Russian Academy of Cosmonautics n.a. K.E.Tsiolkovsky, Honored Scientist of the Russian Federation, double Laureate of the RF Government Prize in Science and Technology, Doctor of Technical Science, Professor, Chief Space Feed Engineer, Director Institute of the Food Concentrate and Special Food Technology ScienceThe subdivision of the Federal Research Centre for Nutrition and Biotechnology 142718, Russia, Moscow Region, Leninsky Area, Ismailovo settlement, 22

Член-корреспондент Международной академии астронавтики, кандидат медицинских наук, заведующий отделом питания, гастроэнтерологии и санитарно-гигиенического контроля условий обитаемости Институт медико-биологических проблем Российской академии наук 123007, РФ, Москва, Хорошевское шоссе , 76 А

Corresponding Member of the International Astronautics Academy, Candidate of Medical Science, Head of the Nutrition, Gastroenterology and Sanitary and Hygiene Control of the Habitable Environment Institute of the Medical and Biological Problems of the Russian Academy of Sciences 123007, Russia, Moscow, Khorosheevskoe High Road, 76A 